\title{
Mobile Work, Mobile Technology: Consequences for decision-making
}

\section{Fabio Miguel Junges}

Business Administration Post Graduate Program - Business School

University of the Sinos Valley - UNISINOS

Porto Alegre/RS

Brazil

\author{
Amarolinda Zanela Klein \\ Business Administration Post Graduate Program - Business School \\ University of the Sinos Valley - UNISINOS \\ Porto Alegre/RS \\ Brazil
}

\section{Claudio Reis Gonçalo}

Business Administration Post Graduate Program

University of the Valley of Itajaí - UNIVALI

Itajaí/SC

Brazil

\section{Carsten Sørensen}

Department of Management Information Systems and Innovation Group

The London School of Economics and Political Science - LSE

London

United Kingdom

Biographical Details

Dr. Fabio Miguel Junges is a researcher at University of the Sinos Valley - UNISINOS, Business School, Brazil. He holds a Ph.D. in Business Administration and a MSc in Management both from UNISINOS. His research interests are related to innovation, mobile technology, mobile decision-making process, ubiquitous computing and digital transformation.

Dra. Amarolinda Zanela Klein is a CNPq (Brazilian National Research Agency) researcher, Ph.D. in Business Administration at FEA/USP (2005), with a post-doctorate at the Université Pierre Mendes France - Grenoble - France. She was PhD research student at the London School of Economics and Political Science (LSE) - London - United Kingdom. She is currently a full professor at the Post Graduate Program in Business Administration at the Business School - University of the Sinos Valley - Brazil.

Dr. Claudio Reis Gonçalo is an Associate Professor at University of the Valley of Itajaí UNIVALI, Brazil. He holds a Ph.D. in Production Engineering from Federal University of Santa Catarina (UFSC), Brazil. He was a visiting researcher at Monash University, Australia. His research interests are related to knowledge management, innovation and strategic management services

Dr Carsten Sørensen is Reader (Associate Professor) in Information Systems and Innovation within Department of Management at The London School of Economics and Political Science, LSE. Dr Sørensen initiated the mobility@1se research network, which aims to study the profound changes to society, organisations and individuals from radical mobilization of work. Dr Sørensen holds a BSc. in mathematics, an MSc in computer science and a Ph.D. in Information Systems from Aalborg University, Denmark. Dr. Sørensen has the 
past 30 years been affiliated with a number of Danish, Swedish and British institutions as both lecturer and researcher.

Acknowledgments

We appreciate the CNPq/CAPES support for this research.

\begin{abstract}
This article explores how the decision-making processes that occur during mobile work differ from those that occur in fixed workplaces. We explored if the levels of intuition and rationality change in decision-making processes and how the use of mobile ICT influence the individual's perception of information quality. A qualitative research approach was applied combining a group and individual interviews, and a non-participant observation of a decisionmaking process simulation with 115 participants. The levels of intuition and reasoning in decision-making are not different between fixed and mobile groups. However, there is a perception of lower information quality and difficulties to process information in a mobility context. The time pressure caused by the constant connectivity via mobile devices has potentially adverse consequences for decision-making, increasing individuals' exposure to error. As positive consequences, there is greater agility of decision flows related to the use of mobile ICT, especially regarding low complexity decisions.
\end{abstract}

Keywords: Decision-Making, Mobility, Mobile ICT, Mobile Work, Intuition.

\title{
Introduction
}

The decision-making process remains among the main topics in organizational studies due to its relevance (Alisson and Zelikow, 1971; Mintzberg, Raisinghani and Théorêt, 1976; Eisenhardt and Zbaracki, 1992; March, 2009; Rahman and Feis, 2009; Nutt, 2011; Villar et al., 2018). However, although the workforce has been increasingly mobile due to the diffusion of mobile ICT (Wang, Chen and Zhu, 2018), the decision-making processes that occurs during mobile work (e.g. during travelling, visiting, walking around - Yuan et al., 2010; Wright et al., 2014) still requires further investigation. 
The increasing use of mobile Information and Communication Technologies (ICT) relates to the complexity and dynamism of the business environment. It requires new structures and work practices to attend to the demands for evaluation, interpretation, prioritization, and action regarding information resources (Buchana and Naicker, 2014; Sørensen and Landau, 2015). For example, the increasing use of mobile ICT is one of the causes of information overload and, paradoxically, it is also one of the possible solutions to manage the pressures of the information age, stimulating the debate over the ability of managers to make appropriate decisions in this era (Buchana and Naicker, 2014; Wajcman, 2014; Wang, Chen and Zhu, 2018).

Previous studies on decision-making processes in contexts of mobility are related to the technical resources to provide efficiency in information delivery by mobile devices (Sharaf and Chrysanthis, 2002), propositions of mobile decision support systems and mobile analytical systems (Cowie and Burstein, 2007; Kumar et al., 2007; Perez et al., 2010, 2011). Burford and Park (2014) explored the information behaviors of young adults with unlimited access to tablets, revealing that the extensive use of mobile applications (app) lead to a more selected and restricted view of information than that encountered in the wide Web. Recently, Jeske et al. (2016) studied individuals' impulsivity in mobile work, but they focused on specific security-related decisions, reinforcing the claim that there are still few research efforts on the use of mobile technology for decision-making. By analyzing the literature, we conclude that there is a lack of studies that address the understanding of the individual decision-making process in the context of mobility.

Considering this, we explored the following research question: how the decisionmaking processes that occur during mobile work, supported by the use of mobile ICT, differ from those that occur in fixed workplaces, supported by stationary ICT? To investigate this question, we developed a qualitative research combining group interview, individual interviews, and non-participant observation of a decision-making process simulation with two groups of participants: (1) a mobile group, which completed a decision task using mobile 
ICT; and (2) a fixed group, which completed the same decision task in a fixed place supported by stationary ICT. The empirical research involved 115 participants in total. The decision-making process was explored considering the evolution of the theoretical perspective from Simon's bounded rationality to the decision-making process based on two cognitive systems: the intuitive and the rational (Kahneman, 2003b). We have also explored how the use of mobile ICT can influence the individual perception of information quality (Wang and Strong, 1996; Lee et al., 2002; Pipino et al., 2002) during decision-making.

The empirical results revealed that the levels of intuition and reasoning applied in decision-making processes in a context of mobility are not different from decisions made in a fixed workplace. However, there is a perception of lower information quality for decisionmaking accessed via mobile devices and difficulties for the individuals to process information using mobile ICT. Greater agility of decision flows was observed, especially regarding low complexity decisions, as well as greater objectivity in the decision-making. The research results provide insights for managers and decision-makers to understand better and to reflect on the decisions made on the move with the support of mobile ICT.

\section{Theoretical Background}

\section{The decision-making process}

The decision-making process can be described as the set of steps that begins with a change of context and ends with a choice that is committed to an action or inaction (Mintzberg et al., 1976; Tarka, 2017). The studies on the decision-making process evolved from a classical view based on the rationality of the decision maker to a perspective that comprises several cognitive, psychological and intuitive aspects of the individual. Simon's studies $(1947,1955)$ form the basis on which the organizational decision-making process has been understood.

The concept of perfect rationality that dominated scientific knowledge until the middle of the twentieth century was strongly questioned by Simon (1947). According to that 
perspective, from the classical and neoclassical economists, a rational individual has unlimited cognitive capabilities and the decision-making is a process of collecting all the relevant information, generating all possible alternatives, examining their consequences, and finally choosing the best one from all the possibilities (Simon, 1947; Kalantari, 2010; Cristofaro, 2017).

Simon $(1947,1955)$ claim that decision-makers cannot be entirely rational because there are three main restrictions on cognition: incompleteness of information, difficulty in anticipation of all possible consequences and future actions, and limited knowledge of all possible human behaviors (Kalantari, 2010). These limitations are mainly the result of a reduced cognitive capacity to access and process information and physical constraints that are humans' characteristics (Simon, 1947, 1955; Cristofaro, 2017). Although rationality is a goal in any organizational decision-making, the decision maker is limited by cognitive abilities and by the environment, so the decision usually is good enough, rather than the absolute best (Brown, 2004; Kalantari, 2010).

Simon $(1947,1955)$ redefined the human rationality and created the bounded rationality concept, influencing the whole scientific literature concerned with human reasoning, including the management literature (Kalantari, 2010). A critical aspect of Simon's research is his contribution regarding the role of intuition in decision-making, arguing that intuition can be based on previous knowledge and experiences of decision makers (Kalantari, 2010).

The bounded rationality concept has continuously evolved and there are many crossfield studies concerned with the investigation of human reasoning and on the hidden rules that govern our minds, such as studies on heuristics from Kahneman and Tversky (1979), Tversky and Kahneman $(1981,1983)$ and Kahneman (2011). The contemporary theories on decision-making agree that the decision-making process has both conscious and subconscious processes (Kalantari, 2010). 
In this research, we consider that the individual decision-making process relies on two cognitive systems: the intuitive and the rational (Tversky and Kahneman, 1981; Kahneman, 2003a). These two systems explain how the individual addresses the activities of searching, processing and evaluating information to decide (Allinson and Hayes, 1996; Okoli and Watt, 2018). This approach has been accepted by both cognitive psychologists and management researchers (Taggart and Robey, 1981; Gollwitzer and Bayer, 1999; Epstein, 2002; Hodgkinson and Clarke, 2007; Allinson and Hayes, 2012; Frisk and Bannister, 2017; Hodgkinson and Sadler-Smith, 2018; Okoli and Watt, 2018).

The intuitive system involves automatic, fast, widespread and relatively effortless information processing based on the previous experiences of the individual, creating associations and perceptions without his or her conscious attention (Kahneman, 2002, 2003a, 2011; Dane and Pratt, 2007; Hodgkinson and Clarke, 2007). Different theoretical lenses have defined this system as natural (Tversky and Kahneman, 1983), automatic (Bargh, 1996; Bargh and Chartrand, 1999), experimental (Epstein, 2002), tacit (Hogarth, 2001; Keskin, 2005), or System 1 (Kahneman, 2003b, 2003a).

The rational system involves the deliberate and rational processing of information, the development of ideas, logical thinking and engagement of the individual in a procedural and systematic analysis of data and situations (Tversky and Kahneman, 1981; Epstein, 2002). This type of processing occurs when the risks or the attention needed for a task are higher, when an error is detected or when rule-based reasoning is required (Kahneman, 2003b; Hodgkinson and Clarke, 2007; Allinson and Hayes, 2012; Hodgkinson and Sadler-Smith, 2018). This system is called intentional (Bargh and Chartrand, 1999), deliberative (Hogarth, 2001), rational (Epstein, 2002), or System 2 (Kahneman, 2003b, 2003a).

While the intuitive system (1) reflects fast, parallel and automatic thinking, usually loaded with a certain level of emotion, governed by habits and difficult to control or modify, the rational system (2) is responsible for slower, serial and controlled thought, with more effort, relative flexibility and potential rule governance (Kahneman, 2003b, 2011). This 
theoretical lens helped us to explore how the use of mobile ICT influences individuals who make decisions during mobile work and how this context affects both systems (1 and 2). To assess the degree of intuition and rationality in the decision-making process, we used the Cognitive Style Index, developed by Allinson and Hayes (1996) and Scott and Bruce (1995).

\section{Information quality in decision-making}

Information Technology has been increasingly used by organizations to collect, store, and process vast quantities of data, but it has been a challenge to translate all this data into meaningful insights to improve the decision-making processes, create strategic advantages, and improve business (Madnick et al., 2009; Mcafee and Brynjolfsson, 2012; Bumblauskas et al., 2017). These capabilities are essential nowadays, as product and services life cycles have become shorter, and there is a vast amount of information available (Madnick et al., 2009; Bumblauskas et al., 2017; Frisk and Bannister, 2017). In this sense, big data has emerged as a new frontier for business to maintain the established competitive advantage or to find new business opportunities (Frisk and Bannister, 2017; Green et al., 2018; Wamba et al., 2018).

Big data refers to a large amount of data sets, which can be in the form of structured and non-structured data, such as voice and videos, real-time information, internal and external data, social media, and any kind of data and information available to be collected, stored or processed by the organization (Chen, Chiang and Storey, 2012; Bumblauskas et al., 2017; Wamba et al., 2018). There is a consensus to define big data as substantial data sets that require specific tools to store, manage, analyze and visualize the data and information that can be extracted from them, and it is usually related to the five V's perspective: volume, velocity, variety, veracity and value of data (White, 2012; Kulkarmi and Tulasidas, 2015; Bumblauskas et al., 2017; Wamba et al., 2018).

With the increasing digitization of processes and services, and the diffusion of digital platforms and social networks, digital data can be easily shared, sliced, diced, recombined and resold (Kallinikos et al., 2013; Reuver et al., 2018) in loosely coupled layers of 
technologies and applications (Yoo et al., 2012). Despite these possibilities, the primary challenge about big data is to generate information that can be transformed into knowledge to make a decision that drive action (Wand and Wang, 1996; Bumblauskas et al., 2017). Artificial intelligence (AI) technologies have been applied with this purpose; tasks currently being performed by AI seek to augment human decision-making through of big-data analytics (Davenport and Ronanki, 2018).

However, before developing big data and AI initiatives, companies must understand which technologies perform what types of tasks, and the strengths and limitations of each. For instance, AI applications based on deep learning are capable of learning from large volumes of labeled data but makes it difficult to understand how it creates their models. This "black box" issue in information generation and decision-making can be problematic in highly regulated industries such as financial services, in which regulators demand knowing why decisions are made in a certain way (Davenport and Ronanki, 2018).

Therefore, the discussion regarding the information quality to support human decision-making becomes more important as organizations seek strategies to harness the big data/AI developments. Information with high quality is that which meets a need of use (Lee et al., 2002; Knight, 2008), and it cannot be defined or measured in absolute terms (Knight, 2008; Tarka, 2017). In the information systems area, information quality can be explained by the degree to which a system can represent the world, supporting the user to make better decisions (Lee et al., 2002; Eand and Wang, 1996; Burstein and Widmeyer, 2007), and it is a foundation of appropriate decision-making and positive outcomes for the organization (Wamba et al., 2018).

In the context of mobility, information quality can be very tricky because the relevant information at a specific moment cannot be considered constant over time (Cowie and Burstein, 2007), and considering that the decision maker context can change quickly, it requires constant reconfigurations on the information used to make a decision (Burstein et al., 2008). Elaluf-Calderwood (2009) showed empirical evidence that the use of mobile ICT 
allows contextual choices during mobile work, taking into account the role improvisation, moods, and self-reference of mobile workers. They experience environmentally contextualized decision-making or work choices, exploiting the opportunities that surround them.

Therefore, the quality of information provided by mobile ICT in this flexible work environment is crucial, and indicators can be used to evaluate it. One of the most important references on information quality is Wang and Strong (1996), which represented it in four categories, subdivided into 16 dimensions as shown in Figure 1. Lee et al. (2002) validated these dimensions, and they allowed us to explore how the use of mobile ICT affects the individuals' perception of information quality for decision-making on the move, as we explain in the next section.

Figure 1 - Information quality for decision-making

\begin{tabular}{|c|c|c|}
\hline Category & Dimension & Definition (The extent that...) \\
\hline \multirow{4}{*}{$\begin{array}{l}\text { Intrinsic Data } \\
\text { Quality }\end{array}$} & Believability & information is deemed believable \\
\hline & Accuracy & information is free of error and reliable \\
\hline & Objectivity & information is impartial, without bias or prejudice \\
\hline & Reputation & information is reliable regarding its origin \\
\hline \multirow{5}{*}{$\begin{array}{l}\text { Contextual Data } \\
\text { Quality }\end{array}$} & Value-added & information adds value and benefits to those who use it \\
\hline & Relevancy & information is relevant and contributes to the task \\
\hline & Timeliness & information is up to date for the task \\
\hline & Completeness & information is complete and suitable for the task \\
\hline & $\begin{array}{l}\text { Appropriate amount } \\
\text { of data }\end{array}$ & $\begin{array}{l}\text { the amount of information handled is appropriate for the } \\
\text { task }\end{array}$ \\
\hline \multirow{4}{*}{$\begin{array}{l}\text { Representational } \\
\text { Data Quality }\end{array}$} & Interpretability & $\begin{array}{l}\text { definitions are clear and the language, symbols, and units } \\
\text { are suitable }\end{array}$ \\
\hline & Ease of understanding & information is properly understood \\
\hline & $\begin{array}{l}\text { Representational } \\
\text { consistency }\end{array}$ & information is consistent over time \\
\hline & $\begin{array}{l}\text { Concise } \\
\text { representation }\end{array}$ & information is presented in a concise and compact form \\
\hline \multirow{3}{*}{$\begin{array}{l}\text { Accessibility } \\
\text { Data Quality }\end{array}$} & Accessibility & is available or easy to access \\
\hline & Access security & $\begin{array}{l}\text { access is appropriately restricted and the information is } \\
\text { stored with security }\end{array}$ \\
\hline & Ease of operation & $\begin{array}{l}\text { the information is easy to operate, combine and } \\
\text { manipulate to suit individual needs }\end{array}$ \\
\hline
\end{tabular}

Source: Wang and Strong (1996) and Lee et al. (2002). 
We applied a qualitative and exploratory approach (Mingers, 2001), which combined different data gathering techniques: a group interview session with 6 participants, a set of 20 semi-structured individual interviews, and a systematic non-participant observation with 89 participants. This combination of techniques aimed to explore the research question from two different perspectives. First, the personal views and opinions of individuals regarding their decision-making processes in a context of mobility, which was achieved through the group and individual interviews. Second, the systematic observation of a concrete case of decisionmaking regarding two different groups of individuals - one group located in a fixed place (supported by stationary ICT) and the other group mobile (supported by mobile ICT). The choice of participants considered: (1) individuals who work at the management level; (2) from different industries (manufacturing, retail, and services); (3) users of mobile ICT in their professional activities; and (4) who frequently work on the move.

\section{Data collection}

First, we conducted a group interview with 6 participants (details in Table 1). It was the starting point for the exploration of relevant research issues, which were used subsequently for the preparation of individual interview scripts. Second, we conducted 20 individual interviews (details also in Table 1) using a semi-structured script that addressed the following issues:

(a) the type of work and mobile ICT used by the interviewee, and the resources accessed to support his decision-making during mobile work;

(b) an analysis (by the interviewee) of a real decision made during mobile work, reporting how the process occurred, the applied tools, perceived difficulties and facilities, and other relevant aspects.

The group and the individual interviews were recorded and later transcribed and organized in an NVivo ${ }^{\circledR}$ database. The analysis considered an open codification process (Saldaña, 2015). 
Table 1 - Group and individual interviews participants

\begin{tabular}{|c|c|c|c|c|}
\hline & Industry & Role & Age & ID \\
\hline \multirow{6}{*}{ 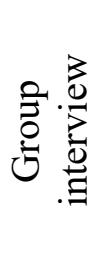 } & Software & Director of Development & 51 & P1 \\
\hline & Plastic Industry & IT Coordinator & 32 & P2 \\
\hline & Electronics Industry & Administrative Officer & 46 & P3 \\
\hline & Industry Thermoplastics & Administrative Officer & 51 & P4 \\
\hline & Software & Commercial Director & 43 & P5 \\
\hline & Information Technology & Technology Director & 36 & P6 \\
\hline \multirow{22}{*}{ 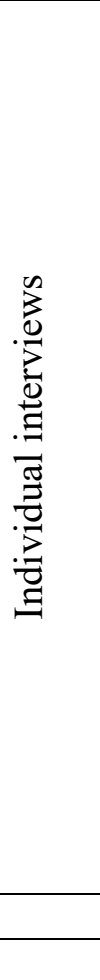 } & Software & Relationship Manager & 41 & E1 \\
\hline & Business consulting & CEO & 53 & E2 \\
\hline & Catholic Church & IT Manager & 50 & E3 \\
\hline & Construction & Administrative Officer & 46 & E4 \\
\hline & Software & Commercial Coordinator & 25 & E5 \\
\hline & Software & Infrastructure Engineer & 32 & E6 \\
\hline & Telecommunications & Technical Supervisor & 45 & E7 \\
\hline & Information Technology & Support Coordinator & 33 & E8 \\
\hline & Software & Pre-Sales Engineer & 34 & E9 \\
\hline & Financial Services & CEO & 65 & E10 \\
\hline & Information Technology & Sales Director & 55 & E11 \\
\hline & Manufacture Technology & Marketing Manager & 38 & E12 \\
\hline & Chamber of Commerce & Regional Manager & 28 & E13 \\
\hline & Digital Security & Regional Manager & 33 & E14 \\
\hline & Information Technology & Technology Director & 36 & E15 \\
\hline & Information Technology & Director of DC / Cloud & 36 & E16 \\
\hline & Business Consulting & Director of Innovation & 46 & E17 \\
\hline & Start-ups Accelerator & CEO & 47 & E18 \\
\hline & Start-ups Accelerator & $\mathrm{CFO}$ & 36 & E19 \\
\hline & Software & Director of Services and HR & 46 & E20 \\
\hline & & \multicolumn{2}{|c|}{ Group interview total duration } & $1 \mathrm{~h} 20 \mathrm{~m}$ \\
\hline & & \multicolumn{2}{|c|}{ Individual interviews total duration } & $15 \mathrm{~h} 48 \mathrm{~min}$ \\
\hline
\end{tabular}

Source: from the research.

We also conducted the systematic non-participant observation of a decision-making simulation. See the simulation protocol summary in Figure 2.

Figure 2 - The decision-making simulation protocol 
DECISION MAKING SIMULATION: to decide who should be hired for a sales job
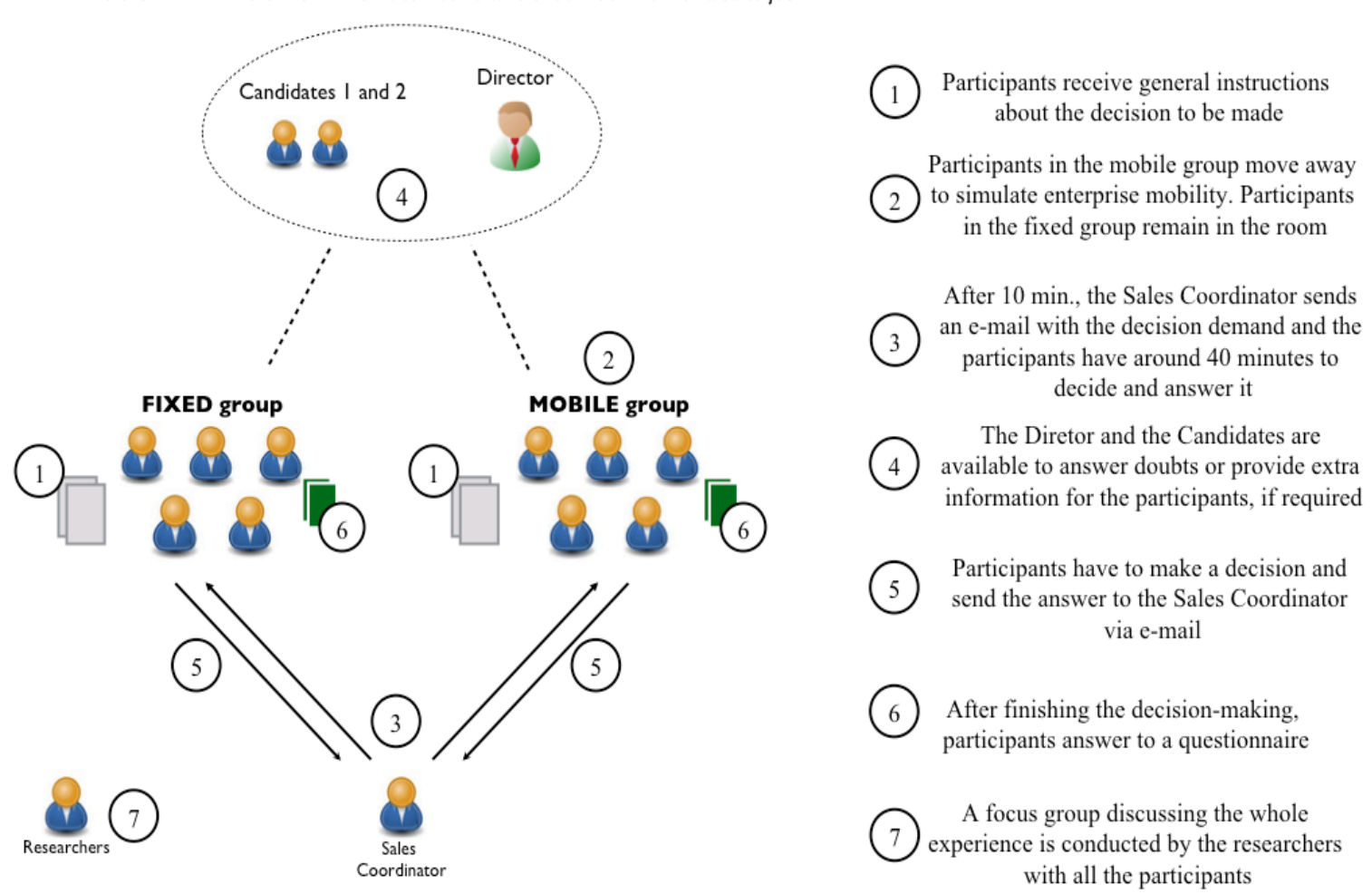

Source: the authors.

As described in Figure 2, in the decision-making simulation each participant held the position of a middle manager at a fictional IT company and received the following decision demand: to decide who should be hired for the position of a salesperson, choosing between two candidates previously assessed and approved by the HR department and by a sales coordinator. Participants in both groups (fixed and mobile) received the decision demand via an e-mail message sent by the sales coordinator, with the candidates' short CVs and links to their pages on social media, such as LinkedIn and YouTube (video presentation), although accessing these links was optional. The two candidates, the director, and the sales coordinator could be contacted by telephone, e-mail, and social media, if necessary; members of the research team played these roles.

Participants in the mobile group received the initial instructions, and they had to walk away for at least 10 minutes before receiving the decision demand via e-mail. They could only use smartphones or tablets during the decision-making process. The participants in the fixed group had the same decision task, but they stayed in a room, also receiving the decision 
task via e-mail. They could only use stationary ICT (notebooks or desktops), and their smartphones could only be used to make phone calls, if necessary. After observing the decision-making simulation, we applied an individual questionnaire and conducted a focus group to explore the impressions about the experience as a whole. The same simulation protocol (Figure 2) was applied in 7 different classes of MBAs, Masters or Ph.D. courses in Management. See the details of participants in Table 2.

Table 2 - Participants in the decision-making process simulation

\begin{tabular}{|c|c|c|c|}
\hline Variables & Fixed Group & Mobile Group & Total \\
\hline Number of participants & 40 & 49 & 89 \\
\hline Average age of participants (years) & 32.6 & 37.7 & 35.4 \\
\hline SD & 9.6 & 9.1 & 9.6 \\
\hline Average time of professional experience (years) & 13.4 & 18.8 & 16.4 \\
\hline SD & 9.1 & 9.0 & 9.4 \\
\hline Average time of management experience (years) & 4.8 & 6.7 & 5.8 \\
\hline $\mathrm{SD}$ & 6.7 & 7.5 & 7.2 \\
\hline Gender & $42 \%$ & $61 \%$ & $53 \%$ \\
\hline Female & $58 \%$ & $39 \%$ & $47 \%$ \\
\hline Undergraduate (incomplete) & $15 \%$ & $2 \%$ & $8 \%$ \\
\hline Undergraduate (complete) & $23 \%$ & $20 \%$ & $21 \%$ \\
\hline Graduate & $62 \%$ & $78 \%$ & $71 \%$ \\
\hline Professional role & $35 \%$ & $31 \%$ & $33 \%$ \\
\hline Coordinator or Supervisor & $30 \%$ & $41 \%$ & $36 \%$ \\
\hline Manager & $12 \%$ & $10 \%$ & $11 \%$ \\
\hline Director & $15 \%$ & $16 \%$ & $16 \%$ \\
\hline Other & $8 \%$ & $2 \%$ & $4 \%$ \\
\hline Research or education & $10 \%$ & $8 \%$ & $9 \%$ \\
\hline Administrative, purchase, operational, assistant & $23 \%$ & $14 \%$ & $18 \%$ \\
\hline Products, $\mathrm{P} \& \mathrm{D}$, analyst, technician, ICT, engineer & $10 \%$ & $43 \%$ & $28 \%$ \\
\hline Sales, marketing, customer relationship, PR & $17 \%$ & $8 \%$ & $12 \%$ \\
\hline HR, training & $22 \%$ & $18 \%$ & $20 \%$ \\
\hline Finances, controller, accountant, fiscal & $10 \%$ & $9 \%$ & $9 \%$ \\
\hline Other & $8 \%$ & $0 \%$ & $4 \%$ \\
\hline
\end{tabular}

Source: from the research.

The individual questionnaire applied after the observation addressed the following issues:

(1) the degree of intuition and rationality applied by the participants in the decisionmaking process, assessed with the Cognitive Style Index (Allinson and Hayes;1996; Scott and Bruce, 1995); 
(2) the level of information quality perceived by the individuals, based on the scale by Wang and Strong (1996); and

(3) their sociodemographic information.

We created two additional variables after the simulation: Answer_Time: time (in minutes) elapsed between the receipt of the demand for decision by email and the sending of the response to it, also via e-mail; and Decision_Feedback: number of words in the individual's decision response sent via e-mail.

The quantitative data from the questionnaire were analyzed with descriptive statistic techniques using SPSS ${ }$, and the qualitative data collected during the observation (in field notes, open questions of the questionnaire, and focus group discussions) were organized and codified using NVivo®. The categories of analysis were:

(1) the individuals' perception of the level of intuitiveness and rationality applied in their decision-making process;

(2) the level of information quality for decision-making as perceived by the participants;

(3) the resources used by them to support the decision-making process;

(4) the facilitators and difficulties faced during decision-making.

The methodological research limitations are the following. First, the group interview session and the individual interviews involved male participants only. Second, the decisionmaking observed was only a simulation, and it was not possible to follow ("shadow") each of the participants during the simulation, which is why a questionnaire was applied immediately after it.

\section{Results}

Group and individual interview analysis

The analysis of the group and individual interviews revealed a set of characteristics associated with the decision-making process supported by the use of mobile ICT in a context 
of mobility. First, the data show that mobile ICT brings more decision demands for individuals. Before the adoption of these technologies, it was difficult to receive a decision demand when the individuals were working far from their fixed workplaces. Nowadays, it occurs frequently, and there is a general expectation of receiving a fast answer, with implications for the decision quality due to the lack of time for reflection and analysis of the alternatives for decision (see evidence at the end of this section, in Figure 3).

However, paradoxically, the shortening of time for decisions is also perceived for its positive consequences, such as greater agility in the decision-making process and increasing individual productivity. Agility is more evident in situations in which the decision is less complex, and there is no need for manipulation (production or treatment) of information. There is also evidence (Figure 3) that emphasizes the contribution of mobile ICT to greater objectivity in information production and communications.

In contrast, in decision demands in which the ambiguity of the situation is higher, and the volume of related information is substantial, the respondents perceive more constraints in the use of mobile ICT to support decision-making, claiming that fixed ICT offers more powerful analytical resources. It was evidenced by aspects such as the lower capacity of handling information and poorer capacity of information combination and production through the use of mobile ICT due to the ergonomic limitations of small mobile devices. There was a frequent debate regarding the information quality perceived by the respondents. The metaphor of "dehydrated information" appeared, describing the process of simplification and the inability to obtain the essence of information through the use of mobile ICT in a context of mobility.

The use of mobile ICT during mobile work was recognized as beneficial, allowing decision demands to reach managers, but also as a burden, because it triggers information flows and decisions that eventually would not need to be made at the time they are demanded or that would not necessarily require the managers' participation. The implications of mobile ICT use are diverse, often causing an excess of information flows and demands of 
interactions and decisions to which individuals must respond (often unnecessarily), potentially creating interruptions.

Superficiality and less attention in the analysis of information also emerged from the interviews, due to multitasking habits and fast interactions and due to engagement and disengagement in different activities/contexts at the same time. The blurring of boundaries between work time and personal time was also evident. Managers are concerned with continually monitoring activities and interacting rapidly in urgent situations, even at personal times.

Another aspect that emerged was the increasing use of mobile ICT generating more collaboration between individuals who are working distantly from each other. However, there is also a reduction in face-to-face collaboration, which potentially decreases the contextual information acquired during these interactions. Figure 3 shows a summary of these research results, indicating the corresponding evidence.

Figure 3 - Group and individual interviews results summary

\begin{tabular}{|c|c|}
\hline Findings & Evidence \\
\hline $\begin{array}{l}\text { More decision } \\
\text { demands and lack } \\
\text { of time for } \\
\text { reflection }\end{array}$ & $\begin{array}{l}\text { "Today the expectation is that the decision has to be made during the day or perhaps } \\
\text { during the shift; [people usually think] because I've sent an e-mail or WhatsApp to him, } \\
\text { he will answer me immediately" (E17). } \\
\text { "Another bad thing is this speed of information and pressure for answering; it increases } \\
\text { your chance of making mistakes because in a hurry you make more mistakes [...] You are } \\
\text { pressured by time to make a decision" (E10). }\end{array}$ \\
\hline $\begin{array}{l}\text { Time pressure on } \\
\text { decision demands }\end{array}$ & $\begin{array}{l}\text { "Because that's what it seems that society wants, that you keep all the balls in the air. If } \\
\text { you stop for a moment to look around, then the balls fall over your head" (E17). } \\
\text { "Now you arrive at work in the morning and have e-mails and Skype messages, and you } \\
\text { do not have time to prepare yourself. You already enter into a fast workflow" (E10). }\end{array}$ \\
\hline $\begin{array}{l}\text { Difficulties to } \\
\text { process } \\
\text { information with } \\
\text { mobile devices }\end{array}$ & $\begin{array}{l}\text { "I will tell you that, for any decision involving attachments, I do not use the phone; it is } \\
\text { very rare" (E13). } \\
\text { "When you need to read lots of information and make queries in multiple databases, I'm } \\
\text { sure this [mobile device] is not the most appropriate tool [...] when we are operating } \\
\text { through a mobile platform, there is a difficulty to see the whole picture" (E15). } \\
\text { "It's hard for you to write a long email in which you need to show data and stuff, so I } \\
\text { postpone it until I am at the office" (E8). }\end{array}$ \\
\hline $\begin{array}{l}\text { "Dehydrated } \\
\text { information" } \\
\text { received via mobile } \\
\text { ICT }\end{array}$ & $\begin{array}{l}\text { "So this abstraction, this representation, that modeling of reality that we can carry inside } \\
\text { computer systems, it is basically like when you freeze meat, and when you thaw it, the } \\
\text { "juice" that was in the cells goes away. If that water is removed, the meat becomes } \\
\text { tasteless, and the information is dehydrated; we make decisions based on dehydrated } \\
\text { information" (E17). }\end{array}$ \\
\hline $\begin{array}{l}\text { Increased } \\
\text { availability for } \\
\text { decision-making }\end{array}$ & $\begin{array}{l}\text { "So, I mean, she eventually got it solved, I did not need to be involved in that situation } \\
\text { [...] This brings me some problems. Being so available brings you harassment too" } \\
\text { (E15). } \\
\text { "At the moment you interact so much with people from your team, the trend is to reach } \\
\text { out more and more from these standard time schedules, business hours. Why? Because it }\end{array}$ \\
\hline
\end{tabular}




\begin{tabular}{|c|c|}
\hline & is usually a time when you are more available" (E20) \\
\hline $\begin{array}{l}\text { Interruptions, } \\
\text { multi-tasking, and } \\
\text { superficiality in } \\
\text { decision-making }\end{array}$ & $\begin{array}{l}\text { "Interruptions hinder me. No doubt, you're doing an activity, and you are interrupted } \\
\text { several times" (E4). } \\
\text { "But I have a habit: if I have a little time left between one task and another, I click there, } \\
\text { and I'm answering [messages in the smartphone] [...] Sometimes I'm talking to someone } \\
\text { in a Web conference, and I am also answering to two or three things" (E15). } \\
\text { "I think with this [the smartphone], today I'm more superficial. I analyze less. Maybe it } \\
\text { enhances a feature that I have, which is my anxiety" (E19). }\end{array}$ \\
\hline $\begin{array}{l}\text { Increased } \\
\text { objectivity in } \\
\text { decision-making }\end{array}$ & $\begin{array}{l}\text { "I see a benefit that is eventually the higher degree of objectivity that an e-mail might } \\
\text { have, and we don't always have in face to face contacts [...](E4). } \\
\text { "Especially when using mobile devices, the trend is that you communicate briefly; you are } \\
\text { straightforward. You will not be able to express your feelings. Mobility cuts you a little } \\
\text { this part of the communication. Especially when you deal with people, this can be lost" } \\
\text { (E6). }\end{array}$ \\
\hline $\begin{array}{l}\text { Greater agility and } \\
\text { productivity in } \\
\text { [less complex] } \\
\text { decision-making }\end{array}$ & $\begin{array}{l}\text { "It's the good side: the speed of information, the speed of decisions is very high [...] we we } \\
\text { can meet a greater number of customers' demands than before this mobile technology" } \\
\text { (E10). } \\
\text { "I answer when it is a simple decision, with fast and brief information, and when it } \\
\text { doesn't need a consultation with other persons or documents or is something that needs to } \\
\text { be elaborated. Then I usually answer it quickly" (E20). }\end{array}$ \\
\hline
\end{tabular}

Source: from the research.

Analysis of the decision-making process simulation (fixed $x$ mobile group)

First, we analyzed and compared the resources used by the two groups during the decision-making simulation. It is worth remembering that the decision-making consisted of choosing one of two candidates for a salesperson position, and for each candidate, there were several information sources available. The participants could call the candidates; and they could access their profiles on social media, video presentations, and full CVs, among other resources. Table 3 shows the use of the available resources by the participants.

Table 3 - Resources used in the decision-making process

\begin{tabular}{|l|c|c|c|c|}
\hline \multirow{2}{*}{ Resource } & \multicolumn{2}{|c|}{ Fixed Group } & \multicolumn{2}{c|}{ Mobile Group } \\
\cline { 2 - 5 } & Number & Participation \% & Number & Participation \% \\
\hline Telephone call & - & - & 6 & 12.2 \\
\hline WhatsApp & - & - & 2 & 4.1 \\
\hline Web search & 3 & 7.5 & 6 & 12.2 \\
\hline $\begin{array}{l}\text { Productivity tools (e.g., } \\
\text { spreadsheet, calculator) }\end{array}$ & 5 & 12.5 & 2 & 4.1 \\
\hline Facebook & 1 & 2.5 & 3 & 6.1 \\
\hline LinkedIn & 22 & 55.0 & 33 & 67.3 \\
\hline YouTube & 35 & 87.5 & 42 & 85.7 \\
\hline Skype & 2 & 5.0 & 3 & 6.1 \\
\hline Other (SMS) & - & - & 1 & 2.0 \\
\hline
\end{tabular}

Source: from the research. 
As the data in Table 3 show, except for productivity tools, for all of the other resources, there was a higher percentage of use in the mobile group. The fixed group used only one device (a notebook) to support their decision-making, whereas, in the mobile group, $25 \%$ of the participants used more than one device (average 1.24) - usually a smartphone and a tablet - and this difference was statistically significant $(\mathrm{F}=111.110 ; \mathrm{Sig}=0.000)$.

We also asked questions about the activities and resources used in parallel during the decision-making process. In total, there were 14 mentions of activities unrelated to the decision at hand: 2 in the fixed group (5\% of the participants) and 12 in the mobile group $(25 \%)$ - in this group the participants performed multitasking such as interactions in social networks, e-mailing, instant messaging or calling to people unrelated to the simulation.

The participants also mentioned the difficulties perceived in the decision-making process through open questions in the questionnaire. A total of 42 coded excerpts were related to the difficulties perceived: 34 in the mobile group and 8 in the fixed group. A common difficulty in the mobile group was typing on smartphones due to the small size of the keyboard, limiting the speed and generation of content on these devices. There were also difficulties to handle and to display information, especially when the participants switched application screens and tried to combine the visualization of the two candidates' profiles. There were also limitations related to listening to audio and difficulty in watching the videos available, either due to the mobile devices features or the environment in which the mobile decision-maker was (e.g., in noisy or sunny environments). There were also some Internet connection difficulties, especially in the mobile group.

Regarding the facilitators perceived during the decision-making process, there were 130 codified excerpts: 46 in the fixed group and 84 in the mobile group (Table 4). Mobility was perceived as a facilitator in the mobile group since decision-making can occur anywhere. Some participants mentioned, for instance, "...use [of mobile ICT] during a walk in the garden" and "Convenience... to solve problems even away from the office" [from the mobile 
group, anonymous]. Speed and agility in accessing information resources were also cited more often in the mobile group.

Table 4 - Perceived facilitators in decision-making

\begin{tabular}{|l|c|c|}
\hline \multicolumn{1}{|c|}{ Categories } & Fixed Group & Mobile Group \\
\hline Availability of information resources & 27 & 30 \\
\hline Easiness and convenience & 7 & 9 \\
\hline Mobility & 1 & 19 \\
\hline Speed/Agility & 11 & 26 \\
\hline
\end{tabular}

Source: research data.

\section{Information quality}

The information quality considered categories and dimensions suggested by Wang and Strong (1996) and empirically validated by Lee et al. (2002) - see Table 5. The questions were answered using a 5-point Likert scale, (1 is "strongly disagree" and 5 is "strongly agree"). There were no statistically significant differences in the individual perceptions of information quality between the two groups, except in two of the three variables that evaluated the dimension of accessibility data quality: (1) accessibility and (2) ease of combination, which had more positive assessments in the fixed group. There was a certain degree of discomfort in the generation and consumption of information for those who used mobile devices, as already mentioned. 
Table 5 - Comparison of averages: information quality

\begin{tabular}{|c|c|c|c|c|c|c|}
\hline & Variable / & Group* & Average & DP & $\mathrm{F}$ & Sig. \\
\hline & Accuracy & Fixed & 4.08 & .764 & 3.086 & .082 \\
\hline 氙 & & Mobile & 4.24 & .879 & & \\
\hline E $\frac{\pi}{0}$ & Objectivity & Fixed & 3.90 & 1.105 & .302 & .584 \\
\hline & & Mobile & 3.96 & 1.098 & & \\
\hline & Value-added & Fixed & 4.38 & .586 & 2.260 & .136 \\
\hline & & Mobile & 4.08 & .886 & & \\
\hline & Relevancy & Fixed & 4.35 & .622 & 1.295 & .258 \\
\hline 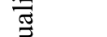 & & Mobile & 4.02 & .878 & & \\
\hline$\tilde{\sigma}$ & Completeness & Fixed & 3.33 & 1.047 & .002 & .965 \\
\hline 苋 & & Mobile & 3.31 & 1.045 & & \\
\hline$\pi$ & Completeness coverage & Fixed & 3.48 & .933 & .855 & .358 \\
\hline$E_{x}$ & & Mobile & 3.33 & 1.068 & & \\
\hline$\stackrel{0}{=}$ & Appropriate amount of & Fixed & 3.50 & .934 & 1.654 & .202 \\
\hline & data & Mobile & 3.31 & 1.084 & & \\
\hline & Volume adequacy & Fixed & 3.35 & 1.075 & .317 & .575 \\
\hline & & Mobile & 3.33 & 1.029 & & \\
\hline & Ease of understanding & Fixed & 4.15 & .770 & .515 & .475 \\
\hline & & Mobile & 4.39 & .759 & & \\
\hline $\overrightarrow{0} \frac{\pi}{0}$ & Representational & Fixed & 4.13 & .757 & .000 & .991 \\
\hline$\stackrel{\breve{b}}{\Xi} \bar{\sigma}$ & consistency & Mobile & 4.24 & .630 & & \\
\hline$\frac{2}{2}=0$ & Concise representation & Fixed & 4.00 & .934 & .670 & .415 \\
\hline & & Mobile & 4.31 & .585 & & \\
\hline & Accessibility & Fixed & $\overline{4.40}$ & .632 & 7.059 & .009 \\
\hline & & Mobile & 4.02 & 1.070 & & \\
\hline$\frac{\pi}{0}$ & Ease of operation & Fixed & 4.15 & .802 & 1.188 & .279 \\
\hline $\begin{array}{ll}2 & \sigma \\
0 & 0 \\
0 & \pi\end{array}$ & & Mobile & 4.04 & 1.040 & & \\
\hline 这 & Ease of combination & Fixed & 4.15 & .864 & 3.766 & .056 \\
\hline & & Mobile & 3.86 & 1.061 & & \\
\hline
\end{tabular}

*Fixed group $n=40$; Mobile group $n=49$.

Source: research data.

\section{Intuition and reason}

Two approaches were used to evaluate whether the decision-making process was more intuitive or rational in the groups. The first was the application of the Cognitive Style Index, developed by Allinson and Hayes (1996) and Scott and Bruce (1995). This instrument includes four items associated with a more intuitive profile and four items associated with a more rational profile, using a 5-point Likert scale (1 is "strongly disagree", and 5 is "strongly agree"). The sum of all four answers in each dimension is assigned as the degree of intuition or reason in the decision, which can vary from 4 to 20 . For each participant, an index was calculated, representing the degree of intuition (variable ED_Intuitive) and the degree of rationality (ED_Rational). According to the data in Table 6, there was no statistically significant difference in the degree of intuition and reason in decision-making between the 
two groups. Both had very similar rates, with slightly more reason than intuition in the decision-making process.

Table 6 - Intuition and reason in decision-making

\begin{tabular}{|l|l|c|c|r|c|}
\hline Group* & Variable & Minimum & Maximum & Average & \multicolumn{1}{c|}{ SD } \\
\hline \multirow{2}{*}{ Fixed } & ED Rational & 7 & 20 & 15.325 & 2.814 \\
\cline { 2 - 6 } & ED Intuitive & 4 & 18 & 12.750 & 2.915 \\
\hline \multirow{2}{*}{ Mobile } & ED Rational & 9 & 20 & 15.020 & 3.126 \\
\cline { 2 - 6 } & ED Intuitive & 7 & 17 & 12.816 & 2.729 \\
\hline
\end{tabular}

*Fixed $n=40$; Mobile $n=49$.

Source: research data.

The second approach to assess the degree of intuition and reason in decision-making was the analysis of the variables "Answer_Time" and "Decision_Feedback" - see Table 7. The analysis of the Answer_Time indicates similar results between the two groups (they took around 30 minutes to send their decision via e-mail). However, the Decision_Feedback showed a significant difference: the individuals in the fixed group generated decisions explained in an average of 101,98 words, while the average number of words used in the mobile group was 56.41 - almost $50 \%$ less. This result can be related to a higher difficulty experienced by the individuals in the mobile group to produce information through mobile devices.

Table 7 - Comparison of averages: answer time and decision feedback

\begin{tabular}{|c|l|r|r|r|c|}
\hline Variable & \multicolumn{1}{|c|}{ Group* } & Average & \multicolumn{1}{c|}{ SD } & F & Sig. \\
\hline \multirow{2}{*}{ Answer_Time } & Fixed & 30.73 & 10.527 & 1.242 & \multirow{2}{*}{.268} \\
\cline { 2 - 4 } & Mobile & 31.84 & 9.315 & & \\
\hline \multirow{2}{*}{ Decision_Feedback } & Fixed & 101.98 & 54.334 & 8.129 & \multirow{2}{*}{.005} \\
\cline { 2 - 4 } & Mobile & 56.41 & 32.294 & & \\
\hline
\end{tabular}

*Fixed $n=40$; Mobile $n=49$.

Source: research data.

\section{Discussion}

The decision-making process has been evolving, as it has been evolving the 
theoretical studies that describe this phenomenon. When we compared the decision-making processes in a fixed location with those that happened in a context of mobility, supported by mobile ICT, we have found evidence that there has been a change in the way the decision process happens, which can be associated with changes in the decision makers' behavior while using mobile technology. Considering the combined results from the group and the individual interviews, and the non-participant observation, we can identify some specific characteristics of the decision-making processes on the move.

The first one is the shortening (or filling) of time spaces for decision-making, as previously discussed in the literature on enterprise mobility (Dourish, 2004; Yoo and Lyytinen, 2005; Sørensen and Landau, 2015). In the group and individual interviews, the respondents indicated that the time pressures and constant connectivity caused by the adoption of mobile ICT have potentially harmful consequences for decision-making, increasing the chance of errors.

Simon $(1947,1955)$ suggested that decision-makers cannot manage all information resources available for a specific decision (bounded rationality). These cognitive restrictions can be even more harmful in the context of mobile work supported by mobile ICT, since the individuals are subject to constant connectivity and an "always-on" status, facing frequent interruptions, dispersion and time fragmentation (Appelbaum et al., 2008; Basoglu et al., 2009; Baethge and Rigotti, 2013; Addas and Pinsonneault, 2018). These aspects were empirically verified, for example, in the decision simulation observed, in which a significantly higher number of participants in the mobile group (14 compared to 2 in the fixed group) that was involved in other interaction flows and multitasking.

The constant connectivity and fast information flow also lead to the "trivialization of decisions" since the individuals have difficulties in prioritizing and differentiating which are the most critical decisions. The use of mobile ICT often acts as a trigger of decision flows that eventually would not need to be made at the time they were required or did not require the involvement of managers. The research data suggest that there is a reduction in the time 
to reflect on the decision to be made in the context of mobility.

Paradoxically, the time pressure and the constant connectivity have also positive consequences: decisions can be faster and occur at any place and any time, increasing organizational agility and flexibility. Moreover, the possibility of using mobile ICT for recording and sharing straightforward information contributes to productivity, especially in less complex decisions.

Regarding the information quality (Wang and Strong,1996) in decision-making processes on the move, the results showed the general perception that the effects of time pressure and the mobilization of interactions lead to a reduction in the information quality produced and consumed through the use of mobile ICT. Remote access to information and communication limits the transfer of the essence of the information, which is often in the context and the subjectivity of face-to-face interactions. The metaphor of "dehydrated information" represents this loss.

When we compare the number of resources that were used by the individuals in the decision-making process, the results show that there was a higher percentage of resources used in the mobile group. It can indicate a tentative of the individuals in this group to search for information to overcome the fact that they were far from the place at which the decisionmaking experience was proposed.

There is another concern related to the amount of data that is consumed and produced with the use of mobile ICT. As previously mentioned, we are facing an exponential increase in big data (White, 2012; Kulkarmi and Tulasidas, 2015; Bumblauskas et al., 2017; Wamba et al., 2018). New digital platforms, social networks and digital services, as well as the integration of once separate systems in the organization can generate an unprecedented amount of information that can be considered in decision-making (Yoo et al., 2012; Reuver et al., 2018). These advancements in technology and information systems have the potential to support decisions to be made more on the basis of data and rigorous reasoning rather than on intuition (McAfee and Brynjolfsson, 2012). 
However, paradoxically, it is also possible that individuals are now confirming, more than ever, Simon's perspective on bounded rationality by their information processing limitations; in this case all data produced by this "big data era" will not necessarily help individuals to make better decision, but will produce useless information, dispersion and waste of time for decision-makers in a context of mobility. It reinforces the need for future applications of innovative technologies, such as AI, to augment and help users to navigate the resources provided by big-data analytics (Davenport and Ronanki, 2018).

We also found evidence that mobile ICT broadens the channels for collaboration via digital media, reducing face-to-face communication and contextual information quality, but, at the same time, these channels stimulate more instantaneous and straightforward interactions, presenting positive consequences. The greater objectivity in decision-making can be related to the difficulties in handling mobile devices, such as difficulties in typing text and comparing information.

For example, when we compare the variables Answer Time and Decision Feedback, we could see that, on average, the mobile group took the same time to answer, but with significantly less generated content to explain their decision, which can lead to a poorer communication in the organization, especially in more complex decision situations.

Regarding possible changes in the degree of intuition or rationality applied in the decision-making process, the analysis showed that the fixed group and the mobile group had similar characteristics, considering an assessment based on the Cognitive Style Index (Allinson and Hayes, 1996). Perhaps the level of intuition and reason in decision-making is related to the individual's profile (past experiences, knowledge, social interactions, among others), which is not directly affected by the use of mobile ICT in a context of mobility. It is also possible that mobility stimulates both types of styles: the intuitive (because decisions must be made quickly due to time pressures and fast information flows), and the rational (since mobile ICT can support the search and analysis of information in different contexts). This issue requires further research, as detailed in the next section. 


\section{Conclusions and future research}

The research goal was to explore how the decision-making processes that occur in a context of mobility, supported by the use of mobile ICT, differ from those that occur in fixed workplaces, supported by stationary ICT. The research results (summary in Figure 4) offers some contributions to the decision-making literature and practice.

Understanding the effects of mobile ICT use in decision-making processes on the move, in practice, can help to enable individuals to explore and strengthen the manners by which these technologies can contribute to this process andto mitigate the constraints and adverse consequences of its use. New habits regarding the use of mobile devices can be encouraged, such as avoiding overlaps and interruptions that generate new activity streams, using face-to-face communication whenever possible, seeking to preserve the division between personal time and professional time, and attempting to keep the focus on the decision at hand. Aspects such as the adoption of new tools to improve collaboration and the reduction of the use of mobile devices in specific work situations (e.g., during complex decisions) are some examples of how organizations could benefit from the research results.

Companies that develop hardware or software solutions for enterprise mobility can also access the research results and consider that, although efforts have been undertaken to reduce the ergonomic discomfort in the use of mobile technologies, application development is still needed to facilitate typing, visualization, and data handling and comparison on smartphone screens. We could see, for instance, that individuals from the mobile group produced in the same time (on average), almost half of content about the decision taken in comparison with the fixed group members. Technologies like speech-to-text can help to fill this gap and promote a significant improvement in the communications in the mobile ICT context. However, contextual conditions related to mobile work (for instance: the place in which the individual is taken the decision - if it is appropriate to talk aloud or not; if there are noises or other types of interferences) should be considered. In mobile work, the context is 
always changing, so the systems that aim to support decision-making should have adaptive and contextual sensitive features.

The constant reconfiguration is a characteristic of the mobile context (ElalufCalderwood, 2009) and requires new information technologies and features that could help the decision maker. It is particularly relevant if we consider the development of big data analytics. As Simon's studies suggest, the value of technology would be based on the ability to collect, filter, and analyze both internal and external data in order to provide individuals with the information needed to make better decisions, without providing useless information. From the company perspective, the business value of information is at the center of big data analytics, IA and other current and future technologies that aim to support decision-making process the information quality has to fit the individuals need in a mobility context.

In Figure 4 we present a set of specific questions for future studies. Whereas this research was exploratory, further research is recommended to confirm the identified elements and to discover new consequences of mobile ICT use during decision-making on the move. We suggest that future studies also address how the use of mobile ICT influences the outcomes of decision-making (the focus here was on the decision-making process itself). We need to advance the understanding of this phenomenon in light of the increasing digital transformation in organizations (Parveen et al., 2016; Keegan and Rowley, 2017).

Figure 4 - Summary of results and questions for future research

\begin{tabular}{|c|c|c|}
\hline Dimension & Results & $\begin{array}{c}\text { Questions for future } \\
\text { research }\end{array}$ \\
\hline $\begin{array}{l}\text { Mobile } \\
\text { decision-making } \\
\text { process (features) }\end{array}$ & $\begin{array}{l}\text { - Increase in decision demands - decision-making can } \\
\text { occur anytime, anywhere, (even during personal } \\
\text { time). } \\
\text { - Involvement of managers in decision flows that do } \\
\text { not need their participation or should not be made at } \\
\text { the moment. } \\
\text { - Increased speed of decision flows and time pressure } \\
\text { leads to greater exposure to errors in decision- } \\
\text { making. } \\
\text { Interruptions, multi-channel interaction flows, and } \\
\text { multitasking can enhance the probability of errors in } \\
\text { decision-making. } \\
\text { Decision demands increasingly overlap with routine } \\
\text { situations, generating difficulties in prioritizing } \\
\text { decisions. } \\
\text { Reduction of time for reflection and preparation for }\end{array}$ & $\begin{array}{l}\text { 1. How do multitasking and } \\
\text { interruptions affect the } \\
\text { quality of decisions made } \\
\text { during mobile work? } \\
\text { 2. How do decision-makers } \\
\text { prioritize the decisions } \\
\text { during mobile work? } \\
\text { 3. How do time pressure and } \\
\text { constant connectivity } \\
\text { affect the quality of } \\
\text { decisions made during } \\
\text { mobile work? } \\
\text { What are the implications } \\
\text { of constant access to } \\
\text { decision makers for the } \\
\text { autonomy of teams? }\end{array}$ \\
\hline
\end{tabular}




\begin{tabular}{|c|c|c|}
\hline & $\begin{array}{l}\text { decision; individuals always "running out of time." } \\
\text { Low-complexity decisions are more flexible and } \\
\text { agile. }\end{array}$ & \\
\hline $\begin{array}{l}\text { Information } \\
\text { quality }\end{array}$ & $\begin{array}{l}\text { - Contextual information quality is reduced via mobile } \\
\text { ICT use ("dehydrated information" metaphor). } \\
\text { - Mobility encourages greater collaboration among } \\
\text { individuals working apart, but the reduction in face- } \\
\text { to-face communication potentially reduces } \\
\text { contextual information quality. } \\
\text { - It is more difficult to handle, compare and prepare } \\
\text { information due to the ergonomic limitations of } \\
\text { mobile devices. } \\
\text { Mobile ICT stimulates more objective and concise } \\
\text { information exchange. }\end{array}$ & 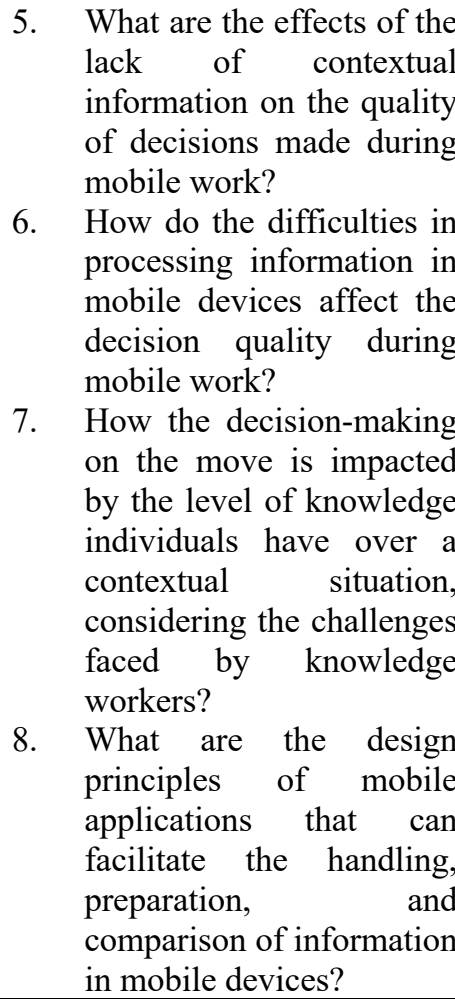 \\
\hline $\begin{array}{l}\text { Intuition and } \\
\text { reasoning }\end{array}$ & $\begin{array}{l}\text { - There are no significant differences in the levels of } \\
\text { intuition and reasoning in the decision-making } \\
\text { processes that occur in a context of mobility (in } \\
\text { comparison with a decision in a "fixed" place). }\end{array}$ & $\begin{array}{l}\text { 9. What are the elements that } \\
\text { can influence the levels of } \\
\text { intuition and reasoning in } \\
\text { decisions made during } \\
\text { mobile work? }\end{array}$ \\
\hline
\end{tabular}

Source: the authors.

\section{References}

Addas, S., and Pinsonneault, A. (2018). 'E-Mail Interruptions and Individual Performance: Is There a Silver Lining?', MIS Quarterly, Vol. 42 No. 2, pp. 381-405.

Alisson, G. and Zelikow, P. (1971). Essence of Decision: Explaining the Cubal Missile Crisis. $2^{\text {nd }}$ Edition. Edited by Longman.

Allinson, C. W. and Hayes, J. (1996). 'The Cognitive Style Index: A Measure of IntuitionAnalysis for Organizational Research', Journal of Management Studies, Vol 33 No. 1, pp. $119-135$.

Appelbaum, S. H., Marchionni, A. and Fernandez, A. (2008). 'The multi-tasking paradox: perceptions, problems and strategies', Management Decision, Vol 46 No. 9, pp. 1313-1325.

Baethge, A. and Rigotti, T. (2013). 'Interruptions to workflow: Their relationship with irritation and satisfaction with performance, and the mediating roles of time pressure and mental demands', Work \& Stress, Vol 27 No. 1, pp. 43-63. 
Bargh, J. A. (1996). Automaticity in social psychology, in Higgins, E. T. and Kruglanski, A. W. (eds) Social psychology Handbook of basic principles. Guilford Press, pp. 169-183.

Bargh, J. A. and Chartrand, T. (1999). 'The unbearable automaticity of being', American Psychological Association, Vol 54 No. 7, pp. 462-479.

Basoglu, K. A., Fuller, M. A. and Sweeney, J. T. (2009). 'Investigating the effects of computer-mediated interruptions: An analysis of task characteristics and interruption frequency on financial performance', International Journal of Accounting Information Systems, Vol 10 No. 4, pp. 177-189.

Brown, R., (2004). 'Consideration of the origin of Herbert Simon's theory of "satisficing" (1933-1947)', Management Decision, Vol 42 No. 10, pp.1240-1256.

Buchana, Y. and Naicker, V. (2014). 'The Effect of Mobile BI on Organisational Managerial Decision-Making', The Journal of Applied Business Research, Vol 30 No. 4, pp. 1003-1018.

Bumblauskas, D., Herb, N., Bumblauskas, P., Amy, I. (2017). 'Big data analytics: transforming data to action', Business Process Management Journal, Vol 23 No. 3, pp.703720.

Burford, S. and Park, S. (2014). 'The impact of mobile tablet devices on human information behavior', Journal of Documentation, Vol 70 No. 4, pp. 622-639.

Burstein, F., Cowie, J., Zaslavsky, A. and Pedro, J. S. (2008). 'Support for real-time decisionmaking in mobile financial applications', Information Systems and e-Business Management, Vol 6 No. 3, pp. 257-278.

Burstein, F. and Widmeyer, G. (2007). 'Decision support in an uncertain and complex world', Decision Support Systems, Vol 43 No. 4, pp. 1647-1649.

Chen, H., Chiang, R.H. and Storey, V.C. (2012). 'Business intelligence and analytics: from big data to big impact', MIS Quarterly, Vol 36 No. 4, pp.1165-1188.

Cowie, J. and Burstein, F. (2007). 'Quality of data model for supporting mobile decisionmaking', Decision Support Systems, Vol 43 No. 4, pp. 1675-1683.

Cristofaro, M., (2017). 'Herbert Simon's bounded rationality: Its historical evolution in management and cross-fertilizing contribution', Journal of Management History, Vol 23 No. 2, pp.170-190.

Davenport, T. H., and Ronanki, R. (2018). 'Artificial intelligence for the real world'. Harvard Business Review, 96(1), 108-116.

Dane, E. and Pratt, M. G. (2007). 'Exploring Intuition and its Role in Managerial Decision Making', Academy of Management Review, Vol 32 No. 1, pp. 33-54.

Dourish, P. (2004). Where the Action Is: The Foundations of Embodied Interaction. MIT 
Press.

Elaluf-Calderwood, S. (2009). 'Organising self-referential taxi work with mICT: the case of the London black cab drivers. PhD thesis', The London School of Economics and Political Science (LSE).

Eisenhardt, K. M. and Zbaracki, M. J. (1992). 'Strategic Decision Making', Strategic Management Journal, Vol 13, pp. 17-37.

Epstein, S. (2002). Cognitive-experiential self-theory of personality, in Millon, T. and Lerner, M. J. (eds) Comprehensive Handbook of Psychology Vol 5 Personality and Social Psychology. John Wiley \& Sons, pp. 159-184.

Frisk, J. E. and Bannister, F. (2017). 'Improving the use of analytics and big data by changing the decision-making culture', Management Decision, Vol 55 No. 10, pp. 20742088 .

Green, S., McKinney, E., Heppard, K, Garcia, L., (2018). 'Big Data, digital demand and decision-making', International Journal of Accounting and Information Management, Vol 26 No. 4, pp.541-555.

Hodgkinson, G. P. and Clarke, I. (2007). 'Exploring the cognitive significance of organizational strategizing: A dual-process framework and research agenda', Human Relations, Vol 60 No. 1, pp. 243-255.

Hodgkinson, G. P. and Sadler-Smith, E. (2018). 'The Dynamics of Intuition and Analysis in Managerial and Organizational Decision Making', Academy of Management Perspectives, 32(4), pp. 473-492.

Hogarth, R. M. (2001). Educating intuition, Applied Cognitive Psychology. University of Chicago Press.

Jeske, D., Briggs, P. and Coventry, L. (2016). 'Exploring the relationship between impulsivity and decision-making on mobile devices', Personal and Ubiquitous Computing, Vol 20 No. 4, pp. 545-557.

Kahneman, D. (2002). Maps of Bounded Rationality: A Perspective on Intuitive Judgment and Choice. Nobel prize lecture, 8, 351-401.

Kahneman, D. (2003a). 'A perspective on judgment and choice: mapping bounded rationality', The American Psychologist, Vol 58 No. 9, pp. 697-720.

Kahneman, D. (2003b). Maps of Bounded Rationality: Psychology for Behavioral Economic, The American Economic Review, 93(5).

Kahneman, D. (2011). Thinking, Fast and Slow. New York: Farrar, Straus and Giroux.

Kahneman, D. and Tversky, A., (1979). 'Prospect Theory: An Analysis of Decision Under 
Risk', Econometrica, Vol 47 No. 2, pp.263-292.

Kalantari, B., (2010). 'Herbert A. Simon on making decisions: Enduring insights and bounded rationality', Journal of Management History, Vol 16 No. 4, pp.509-520.

Kallinikos, J., Aaltonen, A., and Marton, A. (2013). 'The Ambivalent Ontology of Digital Artifacts'. MIS Quarterly, 37(2), 357-370.

Keegan, B. J. and Rowley, J. (2017). 'Evaluation and decision-making in social media marketing', Management Decision, Vol 55 No. 1, pp. 15-31.

Keskin, H. (2005). 'The Relationships Between Explicit and Tacit Oriented KM Strategy, and Firm Performance', Journal of American Academy of Business Cambridge, Vol 7 No. 1, pp. 169-176.

Knight, S. (2008). A Conceptual Framework for Investigating Information Quality in Information Systems, in Information \& Records Management Annual.

Kulkarmi, R.S. and Tulasidas, T.T. (2015). 'Statistics and big data - will they tango?', In Proceedings of the 2015 Decision Sciences Institute Annual Meeting. Seattle, WA.

Kumar, N., Gangopadhyay, A., and Karabatis, G. (2007). 'Supporting mobile decisionmaking with association rules and multi-layered caching', Decision Support Systems, Vol 43 No. 1, pp. 16-30.

Lee, Y. W., Strong, D. M., Kahn, B. K. and Wang, R. Y. (2002). 'AIMQ: a methodology for information quality assessment', Information \& Management, Vol 40, pp. 133-146.

Madnick, S.E., Richard, W. Y., Yang, L. W., Hongwei, Z. (2009). 'Overview and Framework for Data and Information Quality Research', ACM Journal of Data and Information Quality, Vol 1 No. 1), pp.1-17.

McAfee, A. and Brynjolfsson, (2012). 'Big data: the management revolution', Harvard Business Review, Vol 90 No. 10, pp.60-68.

Mingers, J. (2001). 'Combining IS Research Methods: Towards a Pluralist Methodology', Information Systems Research, Vol 12 No. 3, pp. 240-259.

Mintzberg, H., Raisinghani, D. and Théorêt, A. (1976). "The structure of "unstructured" decision processes', Administrative Science Quarterly, Vol 21 No. 2, pp. 246-275.

Nutt, P. C. (2011). 'Making decision-making research matter: some issues and remedies', Management Research Review, Vol 34 No. 1, pp. 5-16.

Okoli, J. and Watt, J. (2018). 'Crisis decision-making: the overlap between intuitive and analytical strategies', Management Decision, Vol 56 No. 5, pp. 1122-1134.

Parveen, F., Jaafar, N. I. and Ainin, S. (2016). 'Social media's impact on organizational performance and entrepreneurial orientation in organizations', Management Decision, Vol 54 
No. 9, pp. 2208-2234.

Pérez, I. J., Cabrerizo, F. J., and Herrera-Viedma, E. (2010). A mobile decision support system for dynamic group decision-making problems. IEEE Transactions on Systems, Man, and Cybernetics-Part A: Systems and Humans, 40(6), 1244-1256.

Perez, I. J., Cabrerizo, F. J. and Herrera-Viedma, E. (2011). 'A mobile group decisionmaking model for heterogeneous information and changeable decision contexts', International Journal of Uncertainty, Fuzziness and Knowledge-Based Systems, Vol 19 No. 1, pp. 33-52.

Pipino, L. L., Lee, Y. W. and Wang, R. Y. (2002). 'Data Quality Assessment', Communications of the ACM, Vol 45 No. 4, p. 211.

Reuver, M., Sørensen, C., and Basole, R. C. (2018). The digital platform: a research agenda. Journal of Information Technology, 33(2), 124-135.

Saldaña, J. The coding manual for qualitative researchers. London: Sage, 2015.

Scott, S. G. and Bruce, R. A. (1995). 'Decision-Making Style: the Development and Assessment of a New Measure', Educational \& Psychological Measurement, Vol 55, pp. 818-831.

Sharaf, M. A. and Chrysanthis, P. K. (2002). 'Facilitating mobile decision-making', Proceedings of the 2nd international workshop on Mobile commerce - WMC '02, p. 45.

Simon, H.A., (1947). Administrative Behavior, F. Press, ed., New York.

Simon, H.A., (1955). 'A Behavioral Model of Rational Choice', The Quarterly Journal of Economics, Vol 69 No. 1, pp.99-118.

Sørensen, C. and Landau, J. S. (2015). 'Academic agility in digital innovation research: The case of mobile ICT publications within information systems 2000-2014', Journal of Strategic Information Systems, Vol 24 No. 3, pp. 158-170.

Taggart, W. and Robey, D. (1981). 'Minds and Managers: on the dual nature of human information processing', Academy of Management Review, Vol 6 No. 2, pp. 187-195.

Tarka, P. (2017). 'Manager's beliefs about marketing research and information use in decisions in the context of the bounded-rationality theory', Management Decision, Vol 55 No. 5, pp. 987-1005.

Tversky, A. and Kahneman, D. (1981). 'The Framing of Decisions and the Psychology of Choice', Science, Vol 211 No. 4481, pp. 453-458.

Tversky, A. and Kahneman, D. (1983). 'Extensional vs. intuitive reasoning: the conjunction fallacy in probability judgment', Psychological Review, Vol 90 No. 4, pp. 293-315.

Villar, E. G.; Walger, C. S.; Abib, G.; Róglio, K. D; Stocker, F (2018). 'Deciding: decision- 
making as a social practice', International Journal of Management and Decision Making, Vol 17 No. 3, pp. 279-298.

Wajcman, J. (2014) Pressed for Time. First. London: The University of Chicago Press.

Wamba, S.F., Akter, S., Trinchera, L., De Bourmont, (2018). 'Turning information quality into firm performance in the big data economy', Management Decision, https://doi.org/10.1108/MD-04-2018-0394.

Wand, Y. and Wang, R. Y. (1996). 'Anchoring data quality dimensions in ontological foundations', Communications of the ACM, Vol 39 No. 11, pp. 86-95.

Wang, R. Y. and Strong, D. M. (1996). 'Beyond Accuracy: What Data Quality Means to Data Consumers', Journal of Management Information Systems, Vol 12 No.4, pp. 5-34.

Wang, Y., Chen, Y. and Zhu, T. (2018). 'Unpacking the organizational impacts of enterprise mobility using the repertory grid technique', Internet Research, Vol 28 No. 1, pp. 143-168.

White, M., (2012). 'Digital workplaces vision and reality', Business Information Review, Vol 29 No. 4, pp.205-214.

Wright, K. B., Abendschein, B., Wombacher, K., O’Connor, M., Hoffman, M., (2014). 'Work-Related Communication Technology Use Outside of Regular Work Hours and WorkLife Conflict', Management Communication Quarterly, Vol 28 No. 4, pp. 507-530.

Yoo, Y. and Lyytinen, K. (2005). 'Social impacts of ubiquitous computing: Exploring critical interactions between mobility, context, and technology', Information and Organization, Vol 15 No. 15 , pp. 91-94.

Yoo, Y., Boland, R., Lyytinen, K., and Majchrzak, A. (2012). 'Organizing for Innovation in the Digitized World'. Organization Science, 23(5), 1398-1408.

Yuan, Y., Archer, N., Connelly, C. E. and Zheng, W. (2010). 'Identifying the ideal fit between mobile work and mobile work support', Information \& Management, Vol 47 No. (3), pp. 125-137. 